\title{
Vacuum Permeator Analysis for Extraction of Tritium From DCLL Blankets
}

\section{Technology of Fusion Energy}

\author{
Paul W. Humrickhouse \\ Brad J. Merrill
}

November 2014

The INL is a

U.S. Department of Energy

National Laboratory

operated by

Battelle Energy Alliance

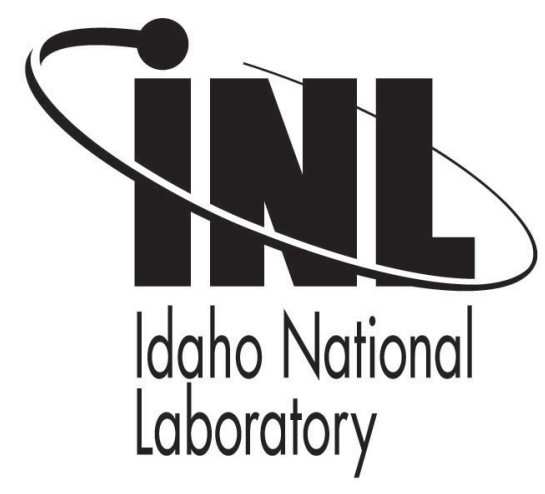

This is a preprint of a paper intended for publication in a journal or proceedings. Since changes may be made before publication, this preprint should not be cited or reproduced without permission of the author. This document was prepared as an account of work sponsored by an agency of the United States Government. Neither the United States Government nor any agency thereof, or any of their employees, makes any warranty, expressed or implied, or assumes any legal liability or responsibility for any third party's use, or the results of such use, of any information, apparatus, product or process disclosed in this report, or represents that its use by such third party would not infringe privately owned rights. The views expressed in this paper are not necessarily those of the United States Government or the sponsoring agency. 


\title{
VACUUM PERMEATOR ANALYSIS FOR EXTRACTION OF TRITIUM FROM DCLL BLANKETS
}

\author{
Paul W. Humrickhouse and Brad J. Merrill \\ Idaho National Laboratory, P.O. Box 1625, MS 3840, Idaho Falls, ID, 83402, paul.humrickhouse@inl.gov
}

\begin{abstract}
It is envisioned that tritium will be extracted from DCLL blankets using a vacuum permeator. We derive here an analytical solution for the extraction efficiency of a permeator tube, which is a function of only two dimensionless numbers: one that indicates whether radial transport is limited by the PbLi or by the solid membrane, and another that is the ratio of axial and radial transport times in the PbLi. The permeator efficiency is maximized by decreasing the velocity and tube diameter, and increasing the tube length. This is true regardless of the mass transport correlation used; we review several and find that they differ little, and the choice of correlation is not a source of significant uncertainty here. The PbLi solubility, on the other hand, is a large source of uncertainty, and we identify upper and lower bounds from the literature data. Under the most optimistic assumptions, we find that a ferritic steel permeator operating at $470{ }^{\circ} \mathrm{C}$ will need to be about twenty times larger in volume than previous conceptual designs using niobium and operating at higher temperatures.
\end{abstract}

\section{INTRODUCTION}

A key safety requirement for any tritium breeding system for a Fusion Nuclear Science Facility (FNSF), demonstration power plant (DEMO), or fusion power plant is minimizing tritium permeation into the reactor building and subsequent release to the environment. The most effective way to meet this requirement is with an efficient tritium extraction system. The Dual-Cooled Lead Lithium (DCLL) breeding blanket, ${ }^{1,2}$ a favored design in US TBM (Ref. 3) and power plant ${ }^{4}$ concepts, is no exception. One significant advantage of the DCLL is that, because of its high temperature and high PbLi flow rate relative to other $\mathrm{PbLi}$ blanket designs, it can achieve high thermal efficiencies. However, the higher flow rates also create somewhat different requirements for the tritium extraction system, which must be able to handle the high throughput while maintaining low tritium concentrations in order to reduce overall system permeation loses. For that reason, the compact mass extractor (gas-liquid contactor) envisioned for the Helium-Cooled Lead Lithium (HCLL) design is probably less suitable for the DCLL (Ref. 5).
Instead, it has been envisioned since the US TBM program $^{3}$ and in subsequent power plant studies ${ }^{4}$ that tritium will be extracted from PbLi using a vacuum permeator. Such a device seeks to exploit the permeation mechanism for extraction by passing the fluid along a high-permeability membrane, with a vacuum maintained on the other side, so as to maximize the concentration gradient across it. The concept has long been in use in gas systems, typically with Pd-Ag membranes. ${ }^{6}$ In $\mathrm{PbLi}$ systems, the situation is slightly more complicated. Unlike in gases, resistance to tritium transport radially across the PbLi boundary layer may be significant; this process may be a limiting factor in the efficiency of the device.

As with gas systems, $\mathrm{PbLi}$ vacuum permeator models $^{4,7}$ originally sought to use high permeability membrane materials, such as alloys of niobium or tantalum, which could operate at high temperatures (700$730{ }^{\circ} \mathrm{C}$ ). While excellent for their high permeability, these group 5 metals readily oxidize at high temperatures even at extremely low oxygen partial pressures. ${ }^{8}$ In addition, corrosion will result in some niobium circulating in the $\mathrm{PbLi}$, which may be activated in the blanket and lead to long term waste disposal concerns. Therefore, a permeator employing more conventional materials such as RAFM steel is of considerable interest; it would need to operate at lower temperatures $\left(\sim 470{ }^{\circ} \mathrm{C}\right)$ to prevent excessive corrosion of the RAFM in PbLi (Ref. 9).

In order to better understand the relative importance of different transport phenomena in $\mathrm{PbLi}$ permeators, and how their efficiency scales with various design parameters, we derive here a quasi-2D analytical solution for the concentration profile along the axis of a permeator tube and for the overall efficiency of a permeator. In section III, we use this formulation to assess the feasibility of a ferritic steel permeator.

\section{ANALYTICAL SOLUTION}

\section{II.A. Radial Tritium Transport}

As in its original conception, ${ }^{7}$ we envision a vacuum permeator as an array of $N$ cylindrical tubes of inner diameter $d=2 r_{i}$ and outer diameter $d_{o}=2 r_{o}$ (thickness $r_{o}$ - 
$r_{i}$ ) with tritium-laden $\mathrm{PbLi}$ flowing in their interiors, and a vacuum maintained on the collective exterior. As in previous analyses, ${ }^{3,4,7}$ we consider three radial transport processes, shown schematically in Figure 1.

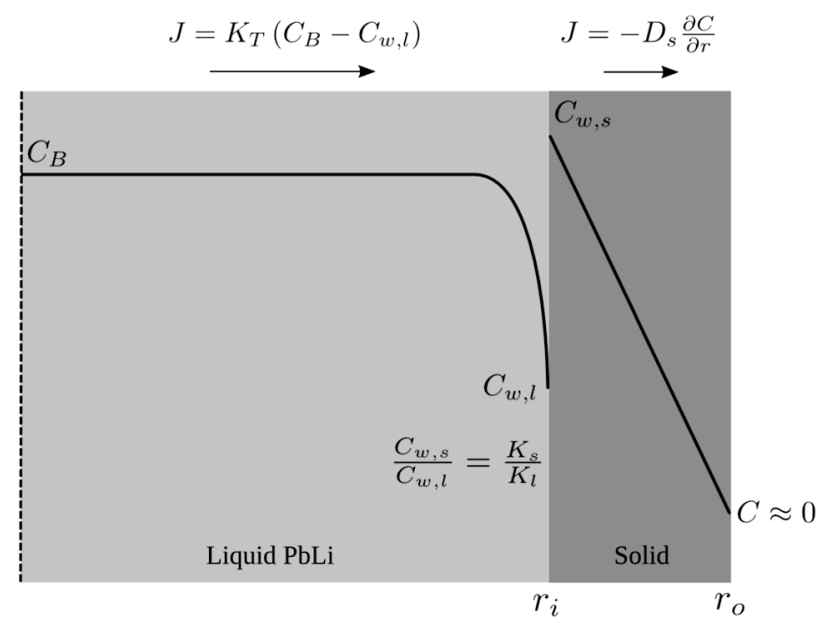

Fig. 1. Schematic of tritium transport processes in the radial direction in a vacuum permeator tube.

The radial flux in the liquid (subscript $l$ ) $\mathrm{PbLi}$ is determined by the mass transport coefficient, $K_{T}(\mathrm{~m} / \mathrm{s})$ :

$$
J_{l}=K_{T}\left(C_{B}-C_{w, l}\right)
$$

where $C_{B}$ and $C_{w, l}\left(\mathrm{~mol} \mathrm{~T} / \mathrm{m}^{3}\right)$ are the tritium concentrations in the bulk and at the wall, respectively. The latter is presumed to be in equilibrium with the solid (subscript $s$ ) concentration $C_{w, s}$ at the same interface, in which case they are related by the ratio of their solubilities:*

$$
\frac{C_{w, s}}{C_{w, l}}=\frac{K_{s}}{K_{l}}
$$

where $K_{s}$ and $K_{l}\left(\mathrm{~mol} \mathrm{~T} /\left(\mathrm{m}^{3} \cdot \mathrm{Pa}^{1 / 2}\right)\right)$ are the solid and liquid solubilities, respectively. The concentration in the solid is given by the well-known solution to the diffusion equation in cylindrical coordinates (see e.g. Ref 10),

$$
C=\frac{C\left(r_{i}\right) \ln \left(r_{o} / r\right)+C\left(r_{o}\right) \ln \left(r / r_{i}\right)}{\ln \left(r_{o} / r_{i}\right)}
$$

Since $C\left(r_{i}\right)=C_{w, s}$ and $C\left(r_{o}\right)$ is assumed to be near zero as a result of the vacuum on the outside of the tubes, Fick's law gives the permeation flux at the interface as

\footnotetext{
${ }^{*}$ Note that when employing the resistance analogy, as is done in Refs. $11-12$, this discontinuity implies an additional (negative) "contact resistance" of the form $\left(1 / h_{c}\right)=\left(\left(K_{l} / K_{s}\right)-1\right) r_{i} \ln \left(r_{o} / r_{i}\right) / D_{s}$.
}

$$
J_{s}=\frac{D_{s} C_{w, s}}{r_{i} \ln \left(r_{o} / r_{i}\right)}
$$

where $D_{s}\left(\mathrm{~m}^{2} / \mathrm{s}\right)$ is the diffusivity in the solid. In terms of diameters, and making use of the interface condition (equation 2), this can be rewritten as follows:

$$
J_{s}=\frac{2 D_{s} C_{w, l}}{d \ln \left(d_{o} / d\right)} \frac{K_{s}}{K_{l}}
$$

Since the radial fluxes across the boundary layer (equation 1) and through the solid (equation 5) must be equal,

$$
K_{T}\left(C_{B}-C_{w, l}\right)=\frac{2 D C_{w, l}}{d \ln \left(d_{o} / d\right)} \frac{K_{s}}{K_{l}}
$$

from which the surface $\mathrm{PbLi}$ tritium concentration $C_{w, l}$ can be written

$$
C_{w, l}=\frac{C_{B}}{\left(1+\frac{2 \Phi_{s}}{K_{T} K_{l} d \ln \left(d_{o} / d\right)}\right)}
$$

where the solid permeability $\Phi_{s}=D_{s} K_{s}$. From equations 1 and 7 an expression for the permeation flux in terms of the bulk concentration can be written:

$$
J=K_{T} C_{B} \frac{\zeta}{(1+\zeta)}
$$

where $\zeta$ is a dimensionless number given by

$$
\zeta=\frac{2 \Phi_{s}}{K_{T} K_{l} d \ln \left(d_{o} / d\right)}
$$

which has a particular significance; it indicates whether the permeation flux is limited by mass transport in the liquid or diffusion in the solid. For $\zeta>1$, the flux simplifies to

$$
J=K_{T} C_{B}
$$

This is the case in which the permeation flux is limited by mass transport in the $\mathrm{PbLi}$. It is identical to equation 1 with $C_{w, l}=0$, and has no dependence on the transport properties in the solid, where in this case diffusion is fast relative to transport in the liquid $\mathrm{PbLi}$. In the opposite $\operatorname{limit} \zeta<<1$,

$$
J=K_{T} C_{B} \zeta
$$


or

$$
J=\frac{2 \Phi_{s}}{K_{l} d \ln \left(d_{o} / d\right)} C_{B}
$$

which is the usual expression for diffusion flux through the solid, multiplied by the solubility ratio. This is the case in which transport is limited by diffusion through the solid; transport in the PbLi is comparatively fast, and thus there is no dependence on $K_{T}$.

The dimensionless number $\zeta$ is thus an important parameter in permeator design. If $\zeta<<1$ for a given set of design parameters, the permeation flux can be improved by choosing a higher permeability material or a thinner wall (but not by increasing the mass transport coefficient $K_{T}$ ); conversely, if $\zeta \gg>1$, the permeation flux can be improved by increasing $K_{T}$ (but not by increasing the permeability or decreasing the wall thickness).

\section{II.B. Axial Tritium Transport}

The preceding analysis gives the radial permeation flux for a fixed bulk tritium concentration $C_{B}$. In a permeator tube, however, the bulk concentration will be continually depleted along its length due to this permeation flux. Therefore, the concentrations $C_{B}, C_{w, 1}$, and $C_{w, s}$ will all be functions of $z$.

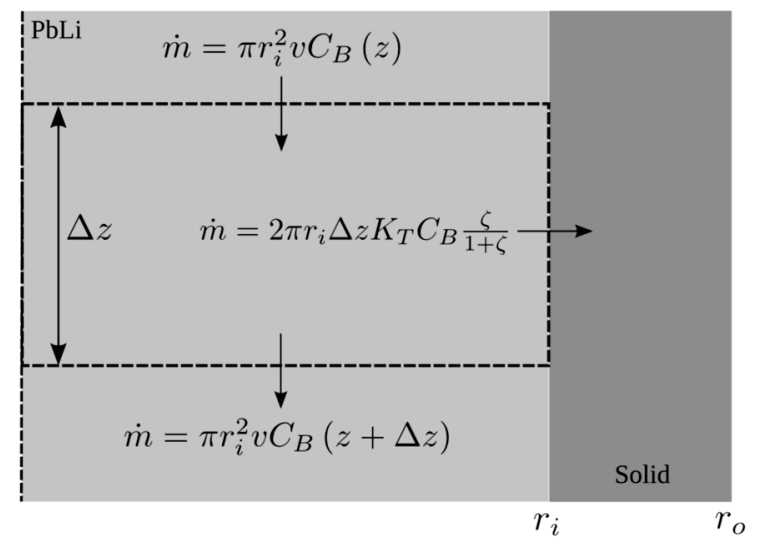

Fig. 2. Tritium balance in a PbLi fluid element.

Consider a fluid element of length $\Delta z$ as shown in Figure 2. For a PbLi velocity $v$, the tritium flow rate $(\mathrm{mol} \mathrm{T/s})$ entering the tube is

$$
\dot{m}_{\text {in }}=\frac{1}{4} \pi d^{2} v C_{B}(z)
$$

and the tritium flow rate exiting the element is

$$
\dot{m}_{\text {out }}=\frac{1}{4} \pi d^{2} v C_{B}(z+\Delta z)
$$

The difference between these two is the permeation flow rate, given by equation 8 times the area:

$$
\dot{m}_{\text {perm }}=\pi d \Delta z J
$$

Balancing the fluxes gives the differential equation for $C_{B}(z)$

$$
\frac{\partial C_{B}(z)}{\partial z}=-\frac{4 K_{T}}{v d} \frac{\zeta}{1+\zeta} C_{B}(z)
$$

For an inlet tritium concentration $C_{B}(0)=C_{0}$, this is solved by

$$
C_{B}(z)=C_{0} \exp \left(-\frac{4 K_{T} z}{v d} \frac{\zeta}{1+\zeta}\right)
$$

\section{II.C. Permeator Efficiency}

Permeation losses (e.g. to the building and environment) elsewhere in the system are driven by the tritium concentration exiting the extraction system. The job of the permeator, then, is to remove whatever fraction of the incoming tritium necessary to achieve the desired exit concentration. This removal fraction, or efficiency, is a convenient parameter for comparison of permeator designs. Using equation 17 , we can identify a permeator length $L$ necessary to achieve a given efficiency $\eta$,

$$
C_{B}(L)=(1-\eta) C_{0}
$$

which gives the following expression for the permeator efficiency:

$$
\eta=1-\exp \left(-\frac{\tau \zeta}{1+\zeta}\right)
$$

where the quantity

$$
\tau=\frac{4 K_{T} L}{v d}
$$

is another dimensionless parameter of significance: it is the ratio of time constants for axial $(L / v)$ and radial $\left(d / 4 K_{T}\right)$ transport in the permeator.

A similar expression for the permeator efficiency is given in Ref. 11,

$$
\eta=1-\exp \left(A^{*} L\right)
$$

where $A^{*}$ was an unknown function of $v, d, d_{o}$, and $K_{T}$, which was later determined by fitting equation 21 to the results of numerical simulations. We see from equation 
19 that for tubes (other geometries will be similar) it has a simple analytical form, which depends on not only $v, d$, $d_{o}$, and $K_{T}$, but also $K_{l}$ and $\Phi_{s}$ (see equation 9 ). Note that $A^{*}$ must have units of inverse length.

\section{II.D. Mass Transport Coefficient}

The mass transport coefficient $K_{T}$ is analogous to the empirical heat transfer coefficient, and is similarly determined by correlations of the form ${ }^{13,14}$

$$
\mathrm{Sh}=\alpha \operatorname{Re}^{\beta} \mathrm{Sc}^{\gamma}
$$

where the Sherwood number Sh, the analogue of the Nusselt number in heat transfer, is defined by

$$
\mathrm{Sh}=\frac{d K_{T}}{D_{l}}
$$

and the Schmidt number Sc, the analogue of the Prandtl number, by

$$
\mathrm{Sc}=\frac{\mu}{\rho D_{l}}
$$

Here $D_{l}\left(\mathrm{~m}^{2} / \mathrm{s}\right)$ is the diffusion coefficient in the liquid, and $\rho$ and $\mu$ the density and viscosity, respectively. Some experimentally determined mass transport correlations applicable for turbulent flow in tubes are summarized in Table I; see also Refs. 15-17 for additional discussion.

The correlation obtained by Harriott and Hamilton ${ }^{18}$ was originally selected by Willms, ${ }^{7}$ and it has since been the de facto mass transport correlation for tritium in PbLi. ${ }^{3-411-12}$ That it was determined with a rather different solute and fluid (benzoic acid in glycerin water) has justifiably led to concerns about its applicability to tritium in PbLi. ${ }^{11-12}$ However, the correlations in Table I, which incorporate a large number of fluids and solutes over a wide range of Reynolds and Schmidt numbers, are remarkably similar, and this gives some confidence in the applicability of the approach, at least in this geometry. In the numerical analysis of section III, we use the correlation by Linton and Sherwood, ${ }^{19}$ as the $\mathrm{Re}^{0.83}$ dependence is verified by multiple experiments, and the $\mathrm{Sc}^{0.33}$ dependence is thought to be more appropriate than $\mathrm{Sc}^{0.44}$ since the latter is obtained from a comparatively narrow range of Schmidt numbers. ${ }^{16}$

But first, we retain the generic coefficients $\alpha, \beta$, and $\gamma$ in what follows so as to draw some conclusions about the permeator efficiency independent of any specific correlation. Solving equation 22 for $K_{T}$ (making use of equations 23 and 24) gives

$$
K_{T}=\frac{\alpha D_{l}^{1-\gamma} v^{\beta} \rho^{\beta-\gamma}}{d^{1-\beta} \mu^{a-\gamma}}
$$

Because, regardless of the correlation used, $\beta>\gamma>0$, all the exponents as written in equation 25 are positive.

We can substitute equation 25 into equation 19 to see how the permeator efficiency depends on the design parameters $v, d$, and $L$. It is easiest to see if we consider the extremes of $\zeta$; for $\zeta>>1$ (liquid-limited),

$$
\eta=1-\exp \left(-\frac{4 \alpha D_{l}^{1-\gamma} L \rho^{\beta-\gamma}}{v^{1-\beta} d^{2-\beta} \mu^{\beta-\gamma}}\right)
$$

and for $\zeta<<1$ (solid-limited),

$$
\eta=1-\exp \left(-\frac{8 \Phi_{s} L}{v K_{l} d^{2} \ln \left(d_{o} / d\right)}\right)
$$

TABLE I. Sherwood Number Correlation Parameters for Turbulent Flow in Tubes.

\begin{tabular}{|l|l|l|l|l|l|}
\hline$\alpha$ & $\beta$ & $\gamma$ & Range & Reference & Notes \\
\hline 0.023 & $4 / 5$ & $1 / 3$ & & Ref. 13,14 & Heat transfer analogy \\
\hline 0.023 & 0.83 & 0.44 & $\begin{array}{l}2000<\mathrm{Re}<35000 \\
0.6<\mathrm{Sc}<2.5\end{array}$ & Ref. 20 & Vaporization of nine different liquids in air \\
\hline 0.0328 & 0.77 & 0.33 & $\begin{array}{l}3000<\mathrm{Re}<40000 \\
0.5<\mathrm{Sc}<3\end{array}$ & Ref. 21 & $\begin{array}{l}\text { Distillation of five different substances in a wetted-wall } \\
\text { column }\end{array}$ \\
\hline 0.023 & 0.83 & $1 / 3$ & $\begin{array}{l}2000<\mathrm{Re}<70000 \\
1000<\mathrm{Sc}<2260\end{array}$ & $\begin{array}{l}\text { Ref. 19 } \\
\text { naphthol in water }\end{array}$ \\
\hline 0.0163 & 0.83 & 0.44 & $\mathrm{Sc} \sim 0.6^{\dagger}$ & Ref. 22 & Vaporization of water in a wetted-wall tower \\
\hline 0.0096 & 0.913 & 0.346 & $\begin{array}{l}10000<\mathrm{Re}<100000 \\
430<\mathrm{Sc}<100000\end{array}$ & Ref. 18 & $\begin{array}{l}\text { Benzoic acid in glycerine-water, and } \\
\text { hydroxymethycellulose solutions }\end{array}$ \\
\hline
\end{tabular}

\footnotetext{
$\dagger$ This correlation has been written in the form given in Ref.16, where $\gamma=0.44$ is assumed based on the correlation obtained in Ref. 20. As the Schmidt number was not varied in these experiments, it does not constitute an independent verification of that dependence.
} 
In both extremes (and thus in all intermediate cases), and for all of the correlations in Table 1, the efficiency 1) increases with $L, 2$ ) decreases with $v$, and 3) decreases with $d$. The latter two points imply, perhaps counterintuitively, that to maximize the permeator efficiency, the Reynolds number should be as low as possible (while still turbulent). There are two reasons for this; 1) increasing the diameter increases the radial distance that tritium must traverse to reach the wall, and 2) increasing the velocity does increase the radial mass transport coefficient $\left(\sim v^{\beta}\right.$, where $\beta<1$ ), but not as effectively as it increases advective transport in the axial direction $(\sim v)$, i.e. the tritium is swept through the length of the permeator tube faster than it is transported radially.

\section{FERRITIC STEEL PERMEATOR}

Making use of the preceding analysis, we consider here the prospects of a ferritic steel vacuum permeator operating at $470{ }^{\circ} \mathrm{C}$, a temperature limit imposed to avoid corrosion of the RAFM steel in PbLi. In order to do so, the temperature dependent material properties $\Phi_{s}, D_{l}, K_{l}$, $\rho$, and $\mu$ must be evaluated.

\section{III.A. RAFM Properties}

A large number of diffusivity and solubility measurements in various RAFM steels have recently been compiled by Causey. ${ }^{23}$ Based on his reported average of all these, we use here the following permeability:

$$
\Phi_{s}=8.72 \times 10^{-8} \exp (-41800 / R T)
$$

Here $\Phi_{s}$ is measured in $(\mathrm{mol} \mathrm{T}) /\left(\mathrm{m} \cdot \mathrm{s} \cdot \mathrm{Pa}^{1 / 2}\right)$ and $R=8.314$ $\mathrm{J} /(\mathrm{mol} \cdot \mathrm{K})$.

\section{III.B. PbLi Properties}

A comprehensive summary of $\mathrm{PbLi}$ properties has recently been given by Mas de les Valls. ${ }^{24}$ There is considerable uncertainty regarding the values of $D_{l}$ and especially $K_{l}$; upper and lower bounds for each are given in Table II with their original references.

\section{III.B.1. The Schmidt Number}

At $470{ }^{\circ} \mathrm{C}$, and given the bounds on the diffusivity $D_{l}$ in Table II,

$$
40<\mathrm{Sc}<150
$$

We note that the correlations in Table I extend far below and above this range of Schmidt numbers, further reinforcing their applicability to $\mathrm{PbLi}$ in these conditions.

\section{III.C. Permeator Optimization}

The preceding analysis allows for the optimization of permeator design based on system constraints. Here we solve for optimum length $L$ and number $N$ of tubes to minimize the total permeator volume $\left(N \pi d_{o}^{2} L / 4\right)$ subject to the following constraints on tube diameter, total $\mathrm{PbLi}$ mass flow rate, efficiency, and allowable pressure drop:

$$
\begin{gathered}
\mathrm{d} \geq 0.01 \mathrm{~m} \\
\dot{m}=\rho N \pi r_{i}^{2} v=26000 \mathrm{~kg} / \mathrm{s} \\
\eta \geq 0.7 \\
\Delta p=f \frac{L}{d} \frac{\rho v^{2}}{2} \leq 1 \mathrm{MPa}
\end{gathered}
$$

where $f$ is estimated (using surface roughness $\varepsilon=2 \mu \mathrm{m}$ ) using $^{25}$

$$
f=-1.8 \log _{10}\left(\frac{6.9}{\operatorname{Re}}+\left(\frac{\varepsilon / d}{3.7}\right)^{1.11}\right)^{-2}
$$

These values are based on the ARIES-CS design ${ }^{4}$ and therefore may be taken as roughly applicable to a DEMO. The $70 \%$ efficiency requirement in that work was set based on the need to keep losses to the environment

TABLE II. PbLi Properties as a Function of Temperature. ${ }^{24}$

\begin{tabular}{|l|l|l|l|l|}
\hline Parameter & Units & Expression & Range & Reference \\
\hline Density & $\mathrm{kg} / \mathrm{m}^{3}$ & $\rho=10520\left(1-\left(1.13 \times 10^{-4} T\right)\right)$ & $508-880 \mathrm{~K}$ & Ref. 24 \\
\hline Viscosity & $\mathrm{Pa} \cdot \mathrm{s}$ & $\mu=1.87 \times 10^{-4} \exp (11640 / R T)$ & $508-625 \mathrm{~K}$ & Ref. 26 \\
\hline Diffusivity (lower bound) & $\mathrm{m}^{2} / \mathrm{s}$ & $D_{l}=2.62 \times 10^{-9} \exp (-6630 / R T)$ & $573-773 \mathrm{~K}$ & Ref. 27 \\
\hline Diffusivity (upper bound) & $\mathrm{m}^{2} / \mathrm{s}$ & $D_{l}=2.50 \times 10^{-7} \exp (-27000 / R T)$ & $573-973 \mathrm{~K}$ & Ref. 28 \\
\hline Solubility (lower bound) & $(\mathrm{mol} \mathrm{T}) /\left(\mathrm{m}^{3} \cdot \mathrm{Pa}^{1 / 2}\right)$ & $K_{l}=1.26 \times 10^{-3} \exp (-1350 / R T)$ & $508-700 \mathrm{~K}$ & Ref. 29 \\
\hline Solubility (upper bound) & $(\mathrm{mol} \mathrm{T}) /\left(\mathrm{m}^{3} \cdot \mathrm{Pa}^{1 / 2}\right)$ & $K_{l}=5.86 \times 10^{-2}$ & $573-723 \mathrm{~K}$ & Ref. 30 \\
\hline
\end{tabular}


below $1 \mathrm{~g} /$ year (99\% efficiency of room detritiation systems was also assumed). The niobium permeator in ARIES-CS (which operated at $730{ }^{\circ} \mathrm{C}$ ) meets the above constraints with 6180 (2060 per $1 / 3$ sector) tubes of $5 \mathrm{~m}$ in length $(v=5 \mathrm{~m} / \mathrm{s})$. Using the lower bound for $K_{l}$ and upper bound for $D_{l}$ from Table II (i.e. the most optimistic assumptions for permeator efficiency), the smallest RAFM permeator that achieves this performance at 470 ${ }^{\circ} \mathrm{C}$ consists of about 19400 tubes of $37.3 \mathrm{~m}$ in length $(v=$ $1.77 \mathrm{~m} / \mathrm{s}$ ). This permeator is larger (in terms of volume) than a PWR steam generator and about 20 times larger than a niobium permeator that satisfies the same constraints at $730{ }^{\circ} \mathrm{C}$ (Table III). The difference in performance between these two membrane materials suggests that permeation is not strictly limited by mass transport in the $\mathrm{PbLi}$, and the fact that $\zeta=0.45$ (near unity) for the RAFM permeator confirms this. In this case, improving either the solid permeation or mass transport in the $\mathrm{PbLi}$ will increase the efficiency of a RAFM permeator. However, as noted previously, the only effective strategy for accomplishing the latter is to decrease the tube diameter. $1 \mathrm{~cm}$ was taken here as a practical lower limit, but smaller sizes can give a considerable increase in performance; it is shown in Table III that decreasing the tube diameter from $1 \mathrm{~cm}$ to $0.5 \mathrm{~cm}$ can achieve the same efficiency with almost half the size and less than half the tube length.

Using the RAFM permeator design with $d=1 \mathrm{~cm}$ described above as a base case, the uncertainty in permeator efficiency associated with both mass transport correlations and diffusivity and solubility data for $\mathrm{PbLi}$ is illustrated in Table IV. These are grouped into upper and lower bounds on efficiency based on the range of diffusivity and solubility data for tritium in PbLi in Table II; the upper bound is defined by high $D_{l}$ and low $K_{l}$, and the lower bound by low $D_{l}$ and high $K_{l}$ (see equations 2627).

For either set of assumptions, the lowest and highest values of $K_{T}$ (and by extension $\zeta$, see equation 9) among the six correlations differ only by about a factor of two. For the upper bound assumptions, $\zeta$ is on the order of (though less than) one, and the permeator efficiency never differs from the $70 \%$ obtained above by more than $5 \%$. For the lower bound assumptions, $\zeta<<1$ (i.e. permeation is solid-limited) and so the efficiency is essentially independent of the mass transport correlation.

Thus, the uncertainty in $\mathrm{PbLi}$ diffusivity and (especially) solubility data implies that we cannot even be sure which transport phenomenon is limiting in this case, and there is a rather large difference in the efficiencies obtained under each set of assumptions (70\% and $3 \%)$. Given this fact, it would be intuitive to refer to the lower bound assumptions as conservative, but this is not necessarily the case. The most relevant metric for the extraction system is not the efficiency, but the outlet tritium concentration, which is what drives permeation losses downstream of the permeator, and it is these losses that must be minimized to maintain public and worker safety. Under the lower bound assumptions, these losses will also be lower. This tradeoff between permeation inside and outside the permeator is dependent on design details of the primary coolant system, and thus a model of this larger system is necessary to determine which set of assumptions is actually the most conservative.

TABLE III. Vacuum Permeator Comparison.

\begin{tabular}{|l|l|l|l|l|}
\hline & Niobium (ARIES-CS $\left.{ }^{4}\right)$ & RAFM $(\mathrm{d}=1 \mathrm{~cm})$ & RAFM $(\mathrm{d}=0.5 \mathrm{~cm})$ & B\&W PWR steam generator \\
\hline Temperature & $730{ }^{\circ} \mathrm{C}$ & $470{ }^{\circ} \mathrm{C}$ & $470{ }^{\circ} \mathrm{C}$ & \\
\hline Efficiency & 0.7 (upper bound) & 0.7 upper bound) & $0.7($ upper bound) & \\
\hline Tubes & $\sim 6180$ & $\sim 19400$ & $\sim 80400$ & $\sim 15000$ \\
\hline Tube length & $5 \mathrm{~m}$ & $37.3 \mathrm{~m}$ & $17.0 \mathrm{~m}$ & $20.74 \mathrm{~m}$ \\
\hline Velocity & $5 \mathrm{~m} / \mathrm{s}$ & $1.77 \mathrm{~m} / \mathrm{s}$ & $1.71 \mathrm{~m} / \mathrm{s}$ & \\
\hline Total Volume & $3.4 \mathrm{~m}^{3}$ & $69.0 \mathrm{~m}^{3}$ & $38.7 \mathrm{~m}^{3}$ & $61.8 \mathrm{~m}^{3}$ \\
\hline$\zeta$ & $124.1(\mathrm{PbLi}$ limited) & 0.45 (transition) & 0.43 (transition) & \\
\hline
\end{tabular}

TABLE IV. Sensitivity to Mass Transport Correlation (RAFM, T $=470{ }^{\circ} \mathrm{C}, d=1 \mathrm{~cm}, L=37.3 \mathrm{~m}, v=1.77 \mathrm{~m} / \mathrm{s}$ ).

\begin{tabular}{|l|l|l|l|l|l|l|l|l|l|}
\hline \multirow{2}{*}{ Correlation } & \multirow{2}{*}{$*$} & \multirow{2}{*}{$\beta$} & \multirow{2}{*}{$\gamma$} & \multicolumn{3}{|c|}{ Upper Bound } & \multicolumn{3}{c|}{ Lower Bound } \\
\cline { 5 - 12 } & & & & $K_{T}(\mathrm{~mm} / \mathrm{s})$ & $\zeta$ & $\eta$ & $K_{T}(\mathrm{~mm} / \mathrm{s})$ & $\zeta$ & $\eta$ \\
\hline Chilton-Colburn $^{13,14}$ & 0.023 & $4 / 5$ & $1 / 3$ & 0.32 & 0.64 & 0.65 & 0.14 & 0.025 & 0.029 \\
\hline Gilliland-Sherwood $^{20}$ & 0.023 & 0.83 & 0.44 & 0.68 & 0.30 & 0.74 & 0.34 & 0.011 & 0.029 \\
\hline Johnstone-Pigford $^{21}$ & 0.0328 & 0.77 & 0.33 & 0.32 & 0.65 & 0.65 & 0.14 & 0.026 & 0.029 \\
\hline Linton-Sherwood $^{19}$ & 0.023 & 0.83 & $1 / 3$ & 0.46 & 0.45 & 0.70 & 0.20 & 0.018 & 0.029 \\
\hline Kasefjian-Plank-Gerhard $^{22}$ & 0.0163 & 0.83 & 0.44 & 0.49 & 0.42 & 0.71 & 0.24 & 0.015 & 0.029 \\
\hline Harriott-Hamilton $^{18}$ & 0.0096 & 0.913 & 0.346 & 0.54 & 0.38 & 0.72 & 0.24 & 0.015 & 0.029 \\
\hline
\end{tabular}




\section{CONCLUSIONS}

There are a number of important points to be emphasized based on the preceding analysis. By deriving an analytical solution, we have shown that the permeator efficiency (i.e. tritium removal fraction) can be described with a simple function of two dimensionless numbers: one indicating whether radial transport in the liquid $\mathrm{PbLi}$ or solid membrane is limiting, and another that is a ratio of axial to radial transport times. Based on the form of correlations for the mass transport coefficient, the permeator efficiency is increased by increasing the tube length, decreasing the tube diameter, and decreasing the $\mathrm{PbLi}$ velocity in the tube (e.g. by adding more tubes).

A review of numerous experimentally measured mass transport coefficients finds that these are quite consistent with each other and with the expected form based on the heat transfer analogy, and that they span a wide range of Schmidt numbers, including those relevant to $\mathrm{PbLi}$. Therefore, there is no reason to suspect they are not applicable to tritium transport in $\mathrm{PbLi}$, nor does the selection of mass transport correlation represent a large source of uncertainty in the present analysis relative to other parameters.

The PbLi diffusivity and solubility (especially the latter), on the other hand, are considerable sources of uncertainty. Considering upper and lower bounds for $D_{l}$ and $K_{l}$ from the literature, for the RAFM permeator parameters determined here, it can only be said that efficiency is between $3 \%$ and $70 \%$.

On the last point, we again emphasize the fact that there is a tradeoff here: high $D_{l}$ and low $K_{l}$ increase permeation everywhere in the system, both in the permeator (where it is desired) and elsewhere (where it is not). Taking a lower $D_{l}$ and higher $K_{l}$ implies a less efficient permeator, but also lower losses elsewhere in the system, i.e. in this case less efficiency is needed. This is a point we intend to investigate further in future work.

Regardless of which assumptions are made regarding these $\mathrm{PbLi}$ properties, it is clear that a permeator with RAFM membranes must be significantly larger $(\sim 20$ times the volume) than previous concepts based on high temperature group 5 metals. In light of that fact, future efforts to identify higher permeability (and/or hightemperature compatible) materials that meet necessary corrosion, activation, and oxidation constraints are probably warranted.

\section{ACKNOWLEDGMENTS}

This material is based upon work supported by the U.S. Department of Energy, Office of Science, Office of Fusion Energy Sciences, under contract number DEAC07-05ID14517.

\section{REFERENCES}

1. S. MALANG et al., "Conceptual design of a dual coolant liquid metal breeder blanket," Fusion Technology 1994: Proceedings of the $18^{\text {th }}$ Symposium on Fusion Technology, Karlsruhe, Germany, August 22-26 1994, Vol. 1, p. 1205, North-Holland (1995).

2. S. MALANG, M. TILLACK, C. P. C. WONG, N. MORLEY, and S. SMOLENTSEV, "Development of the lead lithium (DCLL) blanket concept," Fusion Science and Technology, 60, 249 (2011).

3. B. J. MERRILL et al., US dual coolant lead lithium ITER test blanket module preliminary safety report, INL/EXT-10-18169 rev. 2 (2011).

4. B. J. MERRILL et al., "Safety assessment of the ARIES Compact Stellarator design," Fusion Science and Technology, 54, 838 (2008).

5. B. J. MERRILL, C. P. C. WONG, L. C. CADWALLADER, M. ABDOU, and N. B. MORLEY, "Normal operation and maintenance safety lessons from the ITER US PbLi test blanket module program for a US FNSF and DEMO," Fusion Engineering and Design, 89, 1989 (2014).

6. R. S. WILLMS, P. R. ARZU, K. G. HONNELL, and S. A. BIRDSELL, "Initial testing of a low pressure permeator for tritium processing," Fusion Engineering and Design, 49-50, 963 (2000).

7. R. S. WILLMS, "Tritium extraction from DCLL blanket," Presentation at ITER-TBM-4 Project Meeting, March 2, 2005, http://www.fusion.ucla.edu/ ITER-TBM/ITER-TBM4/TBM\%20Meeting\%200503-02.pdf

8. L. A. CHARLOT and R. E. WESTERMAN, Helium coolant compatibility with candidate fusion reactor structural materials, BNWL-1842 (1974).

9. J. KONYS, W. KRAUSS, Z. VOSS, and O. WEDEMEYER, "Comparison of corrosion behavior of bare and hot-dip coated EUROFER steel in flowing Pb-17Li," Journal of Nuclear Materials, 367-370, 1144 (2007).

10. J. CRANK, The Mathematics of Diffusion, $2^{\text {nd }}$ ed., pp. 69, Oxford University Press, London, UK (1975).

11. P. MARTÍNEZ, C. MORENO, I. MARTÍNEZ, and L. SEDANO, "Optimizing tritium extraction from a Permeator Against Vacuum (PAV) by dimensional design using different tritium transport tools," Fusion Engineering and Design, 87, 1466 (2011).

12. G. VEREDAS et al., "Design and qualification of an on-line permeator for the recovery of tritium from lead-lithium eutectic breeding alloy," Fusion Engineering and Design, 86, 2365 (2011).

13. A. P. COLBURN, "A method of correlating forced convection heat transfer data and a comparison with fluid friction," Transactions of the American Institute of Chemical Engineers, 29, 174 (1933). 
14. T. H. CHILTON and A. P. COLBURN, "Mass Transfer (Absorption) Coefficients: Prediction from Data on Heat Transfer and Fluid Friction," Industrial and Engineering Chemistry, 26, 1183 (1934).

15. T. K. SHERWOOD, R. L. PIGFORD, and C. R. WILKE, Mass Transfer, pp. 211-214, McGraw-Hill, New York, NY (1975).

16. C. O. BENNET and J. E. MYERS, Momentum, Heat, and Mass Transfer, $3^{\text {rd }}$ ed., pp. 583-584, McGrawHill, New York, NY (1982).

17. J. R. WELTY, C. E. WICKS, and R. E. WILSON, Fundamentals of Momentum, Heat, and Mass Transfer, $3^{\text {rd }}$ ed., pp. 656-657, John Wiley and Sons, New York, NY (1984).

18. P. HARRIOTT and R. M. HAMILTON, "Solidliquid mass transfer in turbulent pipe flow," Chemical Engineering Science, 20, 1073 (1965).

19. W. H. LINTON and T. K. SHERWOOD, "Mass transfer from solid shapes to water in streamline and turbulent flow," Chemical Engineering Progress, 46, 258 (1950).

20. E. R. GILLILAND and T. K. SHERWOOD, "Diffusion of vapors into air streams," Industrial and Engineering Chemistry, 26, 516 (1934).

21. H. F. JOHNSTONE and R. L. PIGFORD, "Distillation in a wetted-wall column," Transactions of the American Institute of Chemical Engineers, 38, 25 (1942).

22. R. KAFESJIAN, C. A. PLANK, and E. G. GERHARD, "Liquid flow and gas phase mass transfer in wetted-wall towers," American Institute of Chemical Engineers Journal, 7, 463 (1961).

23. R. A. CAUSEY, R. A. KARNESKY, and C. SAN MARCHI, "Tritium barriers and tritium diffusion in fusion reactors," in Comprehensive Nuclear Materials vol. 4, pp. 511, R. J. KONINGS, Ed., Elsevier, Boston, MA (2012).

24. E. MAS DE LES VALLS et al., "Lead-lithium eutectic material database for nuclear fusion technology," Journal of Nuclear Materials, 376, 353 (2008).

25. S. E. HAALAND, "Simple and explicit formulas for the friction factor in turbulent pipe flow," Journal of Fluids Engineering, 105, 89 (1983).

26. B. SCHULZ, "Thermophysical properties of the Li(17) $\mathrm{Pb}(83)$ alloy," Fusion Engineering and Design, 14, 199 (1991).

27. Y. SHIBUYA, M. AIDA, Y. FUJII, and M. OKAMOTO, "Isothermal release of tritium from neutron-irradiated $\mathrm{Li}_{17} \mathrm{~Pb}_{83}$," Journal of Nuclear Materials, 150, 286 (1987).

28. T. TERAI, S. NAGAI, T. YONEOKA, and Y. TAKAHASHI, "Diffusion coefficient of tritium in molten lithium-lead alloy $\left(\mathrm{Li}_{17} \mathrm{~Pb}_{83}\right)$ under neutron irradiation at elevated temperatures," Journal of Nuclear Materials, 187, 247 (1987).

29. F. REITER, "Solubility and diffusivity of hydrogen isotopes in liquid Pb-17Li," Fusion Engineering and Design, 14, 207 (1991).

30. H. KATSUTA, H. IWAMOTO, and H. OHNO, "Hydrogen solubility in liquid $\mathrm{Li}_{17} \mathrm{~Pb}_{83}$," Journal of Nuclear Materials, 133-134, 167 (1985).

31. F. J. RAHN, A. G. ADAMANTIADES, J. E. KENTON, and C. BRAUN, A Guide to Nuclear Power Technology: a Resource for Decision Making, pp. 347, John Wiley and Sons, New York, NY (1984). 